\title{
TRANSCATHETER CLOSURE OF PATENT DUCTUS ARTERIOSUS: OUR INITIAL EXPERIENCE IN UNIVERSITY OF MALAYA MEDICAL CENTRE
}

\author{
Zarin lkmal Zan Zain, 'Wan Azman Wan Ahmad, Asma Omar, ${ }^{2}$ Mazeni Alwi \\ Departments of Paediatrics and 'Medicine, University Malaya Medical Centre, 50603, Kuala Lumpur, Malaysia, 'Department of Paediatrics, National \\ Heart Institute, Kuala Lumpur, Malaysio
}

\begin{abstract}
Six patients underwent transcatheter closure of patent ductus arteriosus (PDA) using either conventional Gianturco coils or the Amplatzer Ductal Occluder (ADO) device. All patients were females with a median age of 23.3 (range 4 to 26 years). The mean PDA size measured on the lateral aortogram was $3.81 \mathrm{~mm}$ (range $2.3-$ $5.83 \mathrm{~mm}$ ). Complete closure of the PDA was achieved in all patients. (JUMMEC 2000; 1 : 45-47)
\end{abstract}

KEYWORDS: Patent ductus arteriosus, transcatheter device closure

\section{Introduction}

The role of devices to close the patent ductus arteriosus has been popular the last decade due to the ease of deployment and excellent results (1). Although the first device for transcatheter PDA closure was described by Porstmann in 1967, the evolution of the device types and improvement in techniques was limited by too large delivery system especially for children and the complexity in procedural techniques. Furthermore, the success rate was not encouraging and there were significant post-procedure complications.

Earlier reports of transcatheter device closure for PDA using the Rashkind, Botalloccluder, buttoned devices and coils have variable degrees of success with an incidence of residual shunting in $3-38 \%$ of patients.

However, the use of conventional coils and the Amplatzer Ductal Occluder (AGA Medical Corporation, Golden Valley, MN) in major paediatric cardiac centres including the National Heart institute in Kuala Lumpur has shown excellent closure rates with ease of deployment and minimal complications $(1,2)$.

We present our initial experience in transcatheter closure of PDA in six patients between October 1999 and March 2000.

\section{Materials and methods}

\section{Patients}

From October 1999 to March 2000, 6 patients (all females) underwent cardiac catheterization and device closure of a PDA as an alternative to the standard surgical ligation. Written consent was obtained from all patients or guardians of paediatric patients. All patients had clinical and echocardiographic findings of a PDA.

All patients were females with a median age of 23.3 (range 4 to 26 years). The median weight was $30.5 \mathrm{~kg}$ (range $15-47 \mathrm{~kg}$ )

Four patients were asymptomatic with good effort tolerance. Two patients were symptomatic and were on diuretics and inotropes to control heart failure. One patient had associated severe mitral and aortic regurgitation due to rheumatic heart disease but remained in heart failure despite the disease being in remission due to a large PDA (10-mm diameter). She was in NYHA functional class I. Another patient with symptomatic heart failure had severe pulmonary hypertension and was in NYHA functional class IV. Both patients underwent surgical ligation of PDA but still had a large residual shunt following surgery.

\section{Device option and procedure}

The device of choice for closure of the PDA in these patients was decided by the diameter from the lateral descending aortogram. PDA with a diameter of less then $3.5-\mathrm{mm}$ was closed by coils and PDA with a diameter of more than $3.5 \mathrm{~mm}$ was closed by the Amplatzer device.

Corresponding address:

Dr Zarin ikmal Zan Zain

Department of Paediatrics, University Malaya Medical Centre,

50603 Kuala Lumpur, Malaysia

zarn@medicine.med.umedu.my 
All patients underwent a right and left heart catheterization using a $4 \mathrm{~F}$ or $5 \mathrm{~F}$ sheath in the femoral artery and $5 \mathrm{~F}$ to $6 \mathrm{~F}$ sheaths in the femoral vein. Heparin was given at a dose of 50 units $/ \mathrm{kg}$ in all patients. The two paediatric patients (aged 4 years and II years) were under general anaesthesia for the whole duration of the procedure.

Transcatheter deployment of the device was achieved antegradely (from the venous side) in all patients. In one patient, the leading guidewire had to be snared from the arterial side due to difficulty in maneuvering entry into the PDA from the main pulmonary artery.

Deployment of coils was achieved using size $4 \mathrm{~F}$ multipurpose catheters and each coil is delivered via an individual catheter. This is done by inserting more than one catheter sheath per femoral vein.

Delivery of the Amplatzer Ductal Occluder (ADO) is achieved by using a size $7 \mathrm{~F}$ or $8 \mathrm{~F}$ Mullin's catheter and released from its steel wire cable.

A check lateral aortogram is performed before the release of the devices to ensure position and occlusion status. Cineangiogram is taken during the release of the device.

A chest $X$-ray and 20 echocardiogram is done at 24 hours post procedure for reassessment.

\section{Results}

Three patients underwent closure using the Gianturco coils and three others was closed using the Amplatzer Ductal Occluder. The mean PDA size measured on the lateral aortogram was $3.81 \mathrm{~mm}$ (range 2.3-5.83 $\mathrm{mm}$ ). The number of coils used to close the PDA depended on the size of the PDA. Three coils $(5 \mathrm{~cm}$ length $X 8$ $\mathrm{mm}$ helical diameter) were used to close the PDAs sizes
$3.5 \mathrm{~mm}$ and $2.5 \mathrm{~mm}$. Two coils $(5 \mathrm{~cm} \times 8 \mathrm{~mm})$ were used to close the $2.3 \mathrm{~mm}$ PDA.

Complete closure with no residual shunt was achieved immediately after deployment of the coils in als these patients. 2D echocardiogram with Doppler at 24 hours post-procedure reconfirmed closure status.

The larger PDAs were closed with ADO depending on the size of the PDA and the morphology of ductus. In two patients (PDA size $4.8 \mathrm{~mm}$ and $5.83 \mathrm{~mm}$ ), this was achieved by using the size $8 / 10(8 \mathrm{~mm}$ diameter with $10 \mathrm{~mm}$ retention disc) $A D O$, whereas a size $10 / 12$ was needed to close in one other patient (PDA size $4.2 \mathrm{~mm}$ ).

Complete immediate closure was achieved in two patients following ADO release. One patient with a trace shunt upon deployment of the ADO showed very minimal shunt on Doppler echo at 24 hours of procedure and none on reassessment at I month.

The mean pulmonary artery pressures before closure was $27 \mathrm{mmH}$ (range $10-54 \mathrm{mmHg}$ ). There was no significant gradient across the ascending and descending aorta after the procedure.

There was no evidence of left pulmonary artery or aortic obstruction from $2 \mathrm{D}$ echocardiogram on the following day and follow-up at 1 month and 3 months respectively. There was no femoral arterial or venous complication.

All patients were discharged home by 48 hours after the procedure. One patient with symptomatic heart failure who was bedridden in the ward before the procedure achieved quite a drastic improvement in symptoms after the procedure when she was able to ambulate within 24 hours of the procedure.

All patients were reassessed with 2DE at I and 3 months post procedure.

Table 1. Clinical and Closure Data for Patients

\begin{tabular}{cccccccc}
\hline No & Wt $(\mathrm{Kg})$ & Qp/Qs & PDA dia $(\mathrm{mm})$ & Device Type/size & \multicolumn{2}{c}{ Results } \\
\hline 1 & 25 & 1.4 & 5.8 & ADO $8 / 10$ & Immediate & $24 \mathrm{~h}$ & I month \\
2 & 35 & 1.6 & 4.8 & ADO $8 / 10$ & $\mathrm{C}$ & $\mathrm{C}$ & $\mathrm{C}$ \\
3 & 47 & $1.3^{*}$ & 4.2 & ADO $10 / 12$ & $\mathrm{C}$ & $\mathrm{C}$ & $\mathrm{C}$ \\
4 & 32 & 1.1 & 2.3 & $5 \mathrm{~cm} \times 8 \mathrm{~mm}(2)$ & $\mathrm{C}$ & $\mathrm{C}$ & $\mathrm{C}$ \\
5 & 29 & 1.3 & 3.5 & $5 \mathrm{~cm} \times 8 \mathrm{~mm}(3)$ & $\mathrm{C}$ & $\mathrm{C}$ & $\mathrm{C}$ \\
6 & 15 & 1.2 & 2.5 & $5 \mathrm{~cm} \times 8 \mathrm{~mm}(3)$ & $\mathrm{C}$ & $\mathrm{C}$ & $\mathrm{C}$
\end{tabular}

\footnotetext{
Abbreviations:

ADO:Amplatzer Ductal Occluder

TS: Trace shune

$\mathrm{C}$ : Complete closure
}

*The shunt and PDA diameter was underestimated due to significant pulmonary hypertension and distorted anatomy of the pulmonary artery 


\section{Discussion}

Transcatheter closure of PDA is now widely practiced in all major medical institutions with cardiology services especially paediatric cardiology. The National Heart Institute in Kuala Lumpur has been performing these procedures since 1994 with good results using both the conventional coils and the ADO.

After having exposure and hands on experience with these procedures, we report our initial experience on our own patients from the UMMC.

We performed all closures antegradely i.e. deployment of the device from the venous side, using the smaller size 4F catheters for the coils and size 7F or 8F Mullin's catheter for the ADO. The deployment of coils proved to be a more challenging procedure as all the multipurpose catheters are passed through the ductus simultaneously until tight and almost occluding the ductal blood flow and then on sy each coil is released individually.

The lack of a controlled release mechanism seems to be the major disadvantage of the Gianturco coil as it carries the risk of peripheral embolization if not positioned securely. The inability to reposition the coils once extruded also gives the operator a low comfort level. Controlled release coils are being developed to overcome this but is expensive with no added benefit being described (3). The incidence of peripheral pulmonary artery embolization remains between 6.8 $8.7 \%(1,2)$.

The use of conventional Gianturco coils is favoured for the smaller ductuses i.e. less than $3.5 \mathrm{~mm}$ in size in view of the ease of deployment using small catheters (Size 4F and 5F) which is suitable for children reduced costs and excellent closure rates.

The Amplatzer Ductal Occluder requires the use of a Mullin's sheath and a steel wire cable for release. Short term results have showed $100 \%$ closure races at 3 months with very minimal complications in PDA diameters of up to $6 \mathrm{~mm}(1)$. Report from the National Heart Institute (soon to be published) in over 200 patients have also showed $>95 \%$ closure rates in PDAs closed by the ADO.

This self-expandable, mushroom shaped device, made of 0.004 inch thick Nitinol wire has an excellent memory upon expansion and is also delivered via the transvenous route. The rim of the device on the arterial side has a $2 \mathrm{~mm}$ skirt (retention disk) to ensure secure positioning in the ampulla of the PDA.

Deployment of this device proved to be with ease in all our patients but can be difficult the uncommon types of PDA morphology (5).

The use of transcatheter closure of residual PDA after surgery has also shown to be complimentary as in our patients and also described elsewhere (4). In conclusion, transcatheter closure of PDA is a safe and effective procedure in both the paediatric adult age group and is an alternative to surgery in selected group of patients.

\section{References}

1. Masura J, Walsh KP, Thanapoulous B, Chan C, Bass J, Goussous Y, Gavora P, Hijazi ZM. Catheter Closure of Moderate to Large-Sized Patent Ductus Arteriosus Using the New Amplatzer Duct Occluder: Immediate and Short term Results. JAm Coll Cardiol 1998; 15(4): 87882.

2. Alwi M, Kang LM, Samion $H$, Latiff $H A$, Kandavel $G$, Zambahari R. Transcatheter Occiussion of native patent ductus arteriosus using conventional Gianturco coils. Am J Cardiol 1997; 79: 1430-2.

3. Wolfgang AK. Current therapy of the patent ductus arteriosus. Current Opinion in Cardiology 1998, 13:5965.

4. Podnar T, Masura J. Transcatheter Occlusion of Residual Patent Ductus Arteriosus After Surgical Ligation. Pediatr cardiol 199; 20:126-30.

5. Krichenko A, Benson LN, Burrows P, Moes CAF, McLaughtin P, Freedom RM. Angiographic classification of the isolated, persistently patent ductus arteriosus and implications for percutaneous catheter occlusion. Am J Cardiol 1989;67:877-80. 